\title{
Enhanced Flat-Topped Modulation for MMC Control in HVDC Transmission Systems
}

\author{
Rui Li, John E. Fletcher, Senior Member, IEEE, Lie Xu, Senior Member, IEEE, and \\ Barry W. Williams
}

\begin{abstract}
Flat-topped modulation is a member of the family of triplen-series injection techniques that have been extensively utilized in PWM inverter systems to increase the DC-link, and hence semiconductor, utilization. We propose the use of an optimized flat-topped modulation scheme for the modular multilevel converter (MMC) control. The optimized flat-topped waveform minimizes the magnitude of the triplen harmonics, particularly compared to the popular space-vector modulation (SVM) technique, while fully utilizing the DC voltage. This has particular advantages if the converter-side of the interfacing transformer is earthed. Under such conditions, the zero-sequence earthing current is affected by the triplen series injected into the sinusoidal modulating functions. Therefore, it is critical to minimize the injected triplen harmonics. The operating principle of the flat-topped scheme is presented and the Fourier coefficients are compared with the SVM technique. Additionally, the influence of the proposed control scheme on MMC performance is evaluated mathematically. Simulation of a point-to-point HVDC link using average model demonstrates the effectiveness of the proposed MMC operational schemes. The third harmonic of the flat-topped modulation is reduced by $33 \%$, which lowers the potential zero-sequence current flowing to earth. Compared to conventional sinusoidal modulation, the submodule capacitance is reduced by $25 \%$. This significantly lowers submodule cost, volume, and weight. Station conduction losses are expected to reduce by $11 \%$, yielding higher efficiency and lowering cooling system capacity. In addition to the improvement under normal operation, the proposed control scheme also reduces the fault current by $13.4 \%$.
\end{abstract}

Index Terms-HVDC transmission, modular multilevel converter (MMC), flat-topped modulation, space-vector modulation (SVM), submodule capacitance, zero-sequence current.

\section{INTRODUCTION}

$\mathrm{M}$ odular multilevel converters (MMCs) are voltage source converters (VSCs) suited to high-voltage DC (HVDC) transmission systems. With a large number of submodules (SMs) per arm, it can generate a staircase voltage that approximates a sinusoidal waveform, with extremely low

This work was supported by the EPSRC under Grants EP/K006428/1 and EP/K035096, and the NSFC under Grant 51261130484.

R. Li, L. Xu, and B. W. Williams are with the Department of Electronic and Electrical Engineering, University of Strathclyde, Glasgow, G1 1XW UK (e-mail: rui.li@strath.ac.uk, lie.xu@strath.ac.uk, barry.williams@strath.ac.uk).

J. E. Fletcher is with the School of Electrical Engineering and Telecommunications, University of New South Wales, Sydney, N.S.W. 2052, Australia (e-mail: john.fletcher@unsw.edu.au). harmonic distortion; thus no AC filters are needed. Additionally, switching losses are significantly reduced, and low $\mathrm{d} v / \mathrm{d} t$ enables the use of transformers with low insulation requirements [1-5]. Due to these significant advantages, MMC deployment in HVDC system is increasing.

A three-phase transformer is used on the MMC AC-side to isolate the grid and the converter and match the AC and DC voltages. Thus sinusoidal modulation is capable of generating the required voltage and controlling the MMC, although the DC voltage is not fully utilized and consequently neither are the semiconductors. Sinusoidal modulation has good harmonic characteristics and can be simply implemented in digital controllers. As a result, it is widely used as a modulation technique for MMCs [6-8].

Selective harmonic elimination (SHE) modulation is introduced in [9] to control the hybrid multilevel converter and reduce switching losses. However, the active switches of the main power stage still suffer high voltage stresses. Trapezoidal modulation is utilized in the solid-state DC transformer and in the hybrid cascaded MMC in [10] and [11] respectively to reduce switching losses and effectively utilize the DC voltage to produce an output AC voltage with higher fundamental amplitude. However, this is achieved at the expense of higher capital cost and a larger footprint.

By adding zero-sequence components into the reference voltage, discontinuous modulation $[12,13]$ fully utilizes the DC voltage and reduces switching losses. However, additional SMs are required in each arm to avoid over-modulation and reduce SM capacitor voltage ripple. In [14], the second harmonic is injected into the arm current to optimize the current distribution among the SMs and reduce SM capacitor voltage ripple, but at the expense of higher semiconductor current stresses.

Space-vector modulation (SVM), is another attractive approach for MMC control. By injecting triplen harmonics, the DC voltage utilization ratio is increased from $1 / 2$ to $1 / \sqrt{3}$, compared to sinusoidal modulation [15-17]. In [18], the MMC was first proposed for high voltage application and SVM is adopted to effectively utilize the DC voltage. However, it is a burden for the controller to implement the presented SVM. The advantage of SVM over sinusoidal modulation is discussed in [19] and the system performance under a DC fault is improved. However, the influence of SVM during normal operation is not considered.

MMC dynamics under both balanced and unbalanced grid conditions with SVM are evaluated in [17]. However, the 
Electrical and Electronic Engineering Copyright. The copy of record is available at IEEE Xplore Digital Library.

influence of the triplen harmonics on losses and SM capacitance is not considered. Modified space-vector nearest level modulation (NLM) is discussed in [20] to increase the DC voltage utilization ratio thus reduce the DC voltage. However, the reduced DC voltage means a higher DC current requirement in order to transfer rated power, resulting in higher power transmission losses.

In the VSC-HVDC system, the three-phase transformer may use a $\mathrm{Yn} / \mathrm{D}$ configuration where the neutral is earthed on gridside [21, 22]. However, a D/Yn transformer connection with converter-side neutral earthed is introduced in [23-25] to limit the DC overvoltage during a single phase-to-ground fault and a DC pole-to-ground fault.

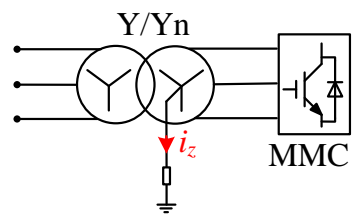

(a)

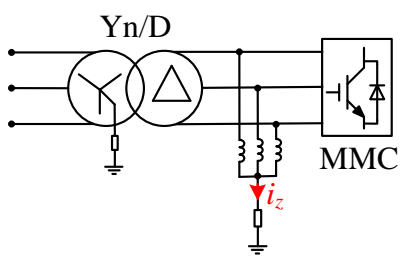

(b)
Fig. 1. Transformer converter-side earthing arrangements in the Zhoushan HVDC project $( \pm 200 \mathrm{kV})$ near Shanghai China (the first 5-terminal MMCHVDC project in the world in operation): (a) Yangshan station and (b) Dinghai and Daishan stations [26-28].

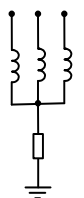

(a)

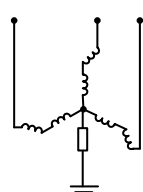

(b)
Fig. 2. Alternative earthing approaches for a $D$ winding of the interface transformer: (a) three-phase earthing reactor [26-28] and (b) zig-zag transformer $[29,30]$.

In the Zhoushan project $( \pm 200 \mathrm{kV})$ near Shanghai China, which is the first 5-terminal MMC-HVDC project in the world and is in operation, Yangshan station uses $\mathrm{Y} / \mathrm{Yn}$ transformer with the converter-side earthed, Fig. 1 (a). Dinghai and Daishan stations use conventional Yn/D transformer with gridside earthed and a three-phase reactor with neutral point earthed through a resistance is connected on the converter-side to earth these two station converters, as shown in Fig. 1 (b) [26-28].

In addition to the three-phase earthing reactor as shown in Fig. 1 (b) and Fig. 2 (a), the zig-zag transformer in Fig. 2 (b) is also capable of providing the earthing point for a $\mathrm{D}$ winding of the interfacing transformer on the converter-side or grid-side $[29,30]$.

However, the earthing point on the transformer converterside provides a zero-sequence current path and the zerosequence component of the converter-side three-phase currents flows to earth through the earthing point. If SVM was adopted, the zero-sequence current $i_{z}$ would be critical due to the high triplen harmonic voltages produced by SVM, which would cause distorted three-phase currents on the converter-side and high losses in the earthing resistance.

To reduce the triplen harmonics in SVM while effectively utilize the DC voltage, a novel flat-topped modulation scheme with reduced zero-sequence harmonics compared with SVM is introduced in [31] to drive a motor and reduce the computational burden for the controller. The flat-topped modulation waveform is simply scaled as the voltage requirement changes, so the injected zero-sequence has a fixed harmonic spectrum with reference to the fundamental. In our proposed Mode II modulation scheme, the injected triplenseries changes dynamically thereby reducing and optimizing the magnitude of the required triplen harmonics. This leads to improved performance in the MMC as will be demonstrated.

This paper aims to enhance the triplen harmonics and fully utilize the DC voltage in order to improve the performance of MMC in a HVDC system. The paper is organized as follows. In Section II, the novel flat-topped modulation scheme for MMC control is proposed and its harmonic characteristics and advantages over SVM are analyzed. The influence of the proposed control scheme on converter losses, SM capacitance, and DC fault currents are discussed in Section III. System performance of the proposed MMC control scheme is assessed by a point-to-point HVDC link using an average model in Section IV. Finally Section V draws conclusions.

\section{ENHANCED FLAT-ToPPED MOdULATION SCHEME}

\section{A. Operating Principle}

The proposed flat-topped modulation is achieved by subtracting a triplen series waveform from the original threephase sinusoidal references. The triplen series waveform is generated by threshold-limiting the sinusoidal references. The technique increases the DC voltage utilization ratio and ensures sinusoidal line voltages at the MMC AC terminals.

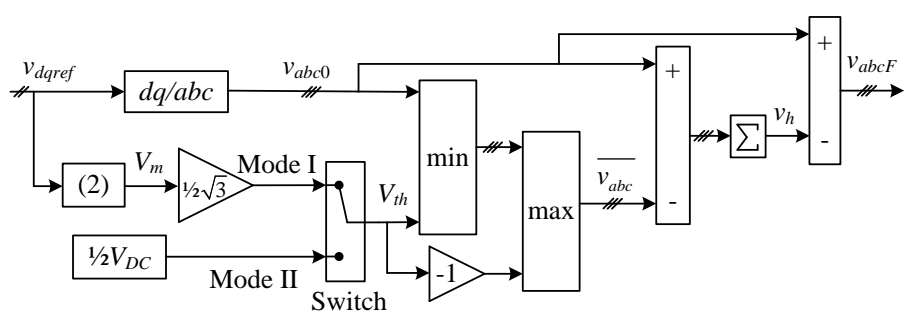

Fig. 3. Proposed flat-topped modulation for MMC control.

As illustrated in Fig. 3, the command voltages $v_{\text {dref }}$ and $v_{\text {qref }}$ $\left(v_{\text {dqref }}\right.$, Fig. 3$)$ are obtained from the current control loop in synchronous rotating coordinates. Transforming $v_{\text {dref }}$ and $v_{\text {qref }}$ to three-phase stationary coordinates, the original three-phase reference voltages $v_{j 0}(j=a, b, c)\left(v_{a b c 0}\right.$, Fig. 3$)$ can be obtained and are assumed as:

$$
\left\{\begin{array}{l}
v_{a 0}=V_{m} \sin (\omega t) \\
v_{b 0}=V_{m} \sin (\omega t-2 \pi / 3) \\
v_{c 0}=V_{m} \sin (\omega t+2 \pi / 3)
\end{array}\right.
$$

where $\omega$ is the grid angular velocity; $V_{m}$ is the fundamental amplitude and is derived by:

$$
V_{m}=\sqrt{v_{\text {dref }}^{2}+v_{\text {qref }}^{2}} .
$$


Limiting the original reference voltages $v_{j 0}(j=a, b, c)$ in the range of $\pm V_{t h}$, the following equation is obtained:

$$
\overline{v_{j}}=\max \left[-V_{t h}, \min \left(V_{t h}, v_{j 0}\right)\right], \quad j=a, b, c
$$

where $V_{t h}$ is voltage threshold and is actively set as:

$$
V_{\text {th }}=\sqrt{3} / 2 V_{m}=\sqrt{3} / 2 \sqrt{v_{\text {dref }}^{2}+v_{\text {qref }}{ }^{2}} .
$$

Subtracting $\overline{v_{j}}\left(\overline{v_{a b c}}\right.$, Fig. 3) from $v_{j 0}$ and summing the resulting three-phase components together yields the required injected signal:

$$
v_{h}=\sum_{j=a, b, c}\left(v_{j 0}-\overline{v_{j}}\right) .
$$

Then the three-phase reference voltages of the flat-topped modulation $v_{j F}(j=a, b, c)\left(v_{a b c F}\right.$, Fig. 3) are derived by injecting the harmonic voltage $v_{h}$ into the original three-phase voltages $v_{j 0}(j=a, b, c)$ :

$$
v_{j F}=v_{j 0}-v_{h}, \quad j=a, b, c .
$$

As shown in Fig. 4 (b), the three-phase voltages $v_{j F}(j=a, b$, c) have flat tops which cover a sextant ( $\pi / 3$ radians) of the fundamental. In a period of $2 \pi / 3 \omega$, the harmonic voltage in Fig. 4 (b) is govern by:

$$
v_{h}=\left\{\begin{array}{ll}
V_{m}\left[\sin (\omega t)-\frac{\sqrt{3}}{2}\right], & -\pi<3 \omega t \leq 0 \\
V_{m}\left[\sin \left(\omega t-\frac{2 \pi}{3}\right)+\frac{\sqrt{3}}{2}\right], & 0<3 \omega t \leq \pi
\end{array} .\right.
$$

The harmonic voltage $v_{h}$ is then expressed by the Fourier series:

$$
v_{h}=\sum_{n=1}^{\infty} \frac{\sqrt{3} V_{m} \sin [(2 n-1) 3 \omega t]}{2 \pi(2 n-1)(3 n-2)(3 n-1)} .
$$
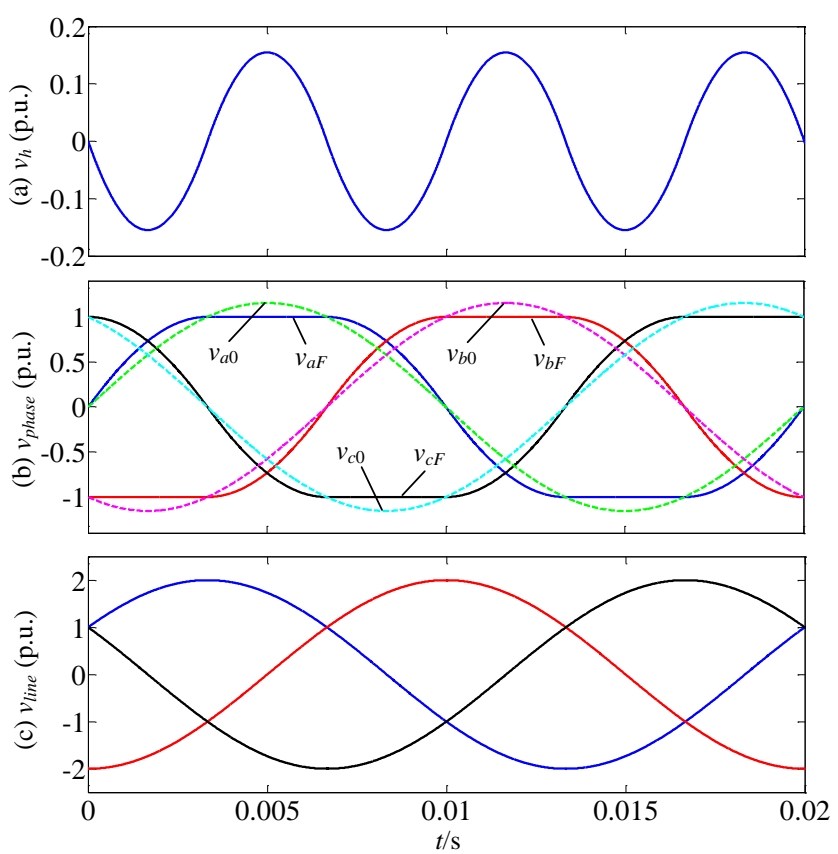

Fig. 4. Reference voltages of the proposed flat-topped modulation for MMC control, normalized to $1 / 2 V_{D C}$ and $m_{h}=2 / \sqrt{3}$ : (a) injected triplen harmonics, (b) phase voltages referenced to the DC-link mid-point, and (c) line voltages.

The harmonic voltage $v_{h}$ contains only triplen harmonics $\left(h=3^{\text {rd }}, 9^{\text {th }}, 15^{\text {th }}, \ldots\right)$, which are cophasal and are not present in the line voltages, as shown in Fig. 4 (c). With $V_{m}$ in the range of $\left(0 \sim V_{D C} / \sqrt{3}\right)$, where $V_{D C}$ is the DC voltage, the peak of reference phase voltage $v_{j F}(j=a, b, c)$ are limited by (3) and (4) and do not exceed $1 / 2 V_{D C}$. Thus, the DC voltage utilization ratio is increased from $1 / 2$ to $1 / \sqrt{3}$, compared to sinusoidal modulation.

The fundamental amplitude $V_{m}$ can be greater than $1 / 2 V_{D C}$ while over-modulation is avoided.

Ignoring the voltage drop across the arm inductances, the transformer leakage inductances, and the grid inductances, a modulation index $m$ is defined as the ratio between the fundamental amplitude and half the DC voltage:

$$
m=\frac{V_{m}}{1 / 2 V_{D C}} .
$$

Thus, the modulation index of the flat-topped modulation $m_{F}$ is in the range of $(0 \sim 2 / \sqrt{3})$. The maximum fundamental amplitude of the phase voltage is increased from $1 / 2 V_{D C}$ (1p.u.) to $V_{D C} / \sqrt{3}$ ( $2 / \sqrt{3}$ p.u. ) by using flat-topped modulation, while output voltage peak remains $1 / 2 V_{D C}$ (1p.u.), as demonstrated in Fig. 4 (b). As a result, with the same peak of output voltage, the relationship between the modulation indices of the flat-topped modulation $m_{F}$ and that of sinusoidal modulation $m_{0}$ is:

$$
m_{F}=2 / \sqrt{3} m_{0} .
$$

\section{B. Comparison between SVM and Flat-Topped Modulation}

The proposed flat-topped modulation has the same voltage generating capability as SVM but with reduced triplen harmonics. From (6) and (8), the phase voltage of the flattopped modulation, referenced to the mid-point of the DC-link, is rewritten as:

$$
v_{a F}=V_{m} \sin (\omega t)+\sum_{n=1}^{\infty} \frac{\sqrt{3} V_{m} \sin [(2 n-1) 3 \omega t]}{2 \pi(2 n-1)(3 n-2)(3 n-1)} .
$$

The components of the triplen harmonics are then derived and listed in Table I. Compared to SVM, the injected triplen harmonics in the proposed flat-topped scheme are enhanced. The dominant third harmonic is reduced from $20.67 \%$ to $13.8 \%$ (by $33 \%$ ) while the voltage generating capability remains unchanged. The triplen harmonics in the flat-topped modulation attenuate faster and are lower than that of SVM. The lower triplen harmonics indicate the proposed scheme can reduce the zero-sequence current flowing to the earth point on the converter-side.

Although the zero-sequence voltage exists in the MMC station with converter-side of the transformer unearthed, the zero-sequence current is always zero as there is no zerosequence current path. However, the zero-sequence voltage causes the voltage variation of transformer terminals. As third harmonic voltage is reduced by $33 \%$ by the proposed control scheme, the voltage variation of transformer terminals is correspondingly reduced.

Additionally, the proposed modulation scheme avoids the sector determination and the calculation of time duration for which the space vector is applied. This makes it easy to implement and does not cause extra computational burden for the controller, even for MMC with several hundred SMs per arm. 
Electrical and Electronic Engineering Copyright. The copy of record is available at IEEE Xplore Digital Library.

SVM is widely used in the control of the two-level VSC, as it gives the lowest switching-frequency generated current ripple compared with other modulation methods, e.g. sinusoidal modulation and dead band modulation [15, 16, 31]. The proposed flat-topped scheme can be used to control twolevel VSC, but its current ripple is slightly higher than SVM, as the top of the proposed approach is flat. However, the current ripple is not a concern in MMC-HVDC application, where the output voltage typically has hundreds of levels and therefore produces minimal AC current ripple. This characteristic makes the proposed flat-topped modulation scheme more suitable for the MMC-HVDC application than for conventional two-level modulation.

Mode I scheme is proposed in [31] to control a two-level VSC and drive a motor. However, the influence of zerosequence harmonics on the converter performance is not considered as low power drive systems are rarely concerned by the impact of the low-frequency common-mode voltage developed by triplen-series injection. In this paper, the application of Mode I in the MMC control is mathematically analysed and its influence on MMC performance is evaluated, where the SM capacitance, station conduction losses, DC fault currents are all significantly reduced.

TABLE I

Comparison of Harmonic Components between SVM and the Flat-Topped Modulation.

\begin{tabular}{l|l|l|l|l|l|l}
\hline \hline \multicolumn{1}{c|}{ COMPONENT } & \multicolumn{1}{c|}{$1^{\text {st }}$} & $3^{\text {rd }}$ & $9^{\text {th }}$ & $15^{\text {th }}$ & $21^{\text {st }}$ & $27^{\text {st }}$ \\
\hline Space-Vector Modulation & 1 & $20.67 \%$ & $2.07 \%$ & $0.74 \%$ & $0.38 \%$ & $0.23 \%$ \\
\hline Flat-Topped Modulation & 1 & $13.8 \%$ & $0.46 \%$ & $0.1 \%$ & $0.04 \%$ & $0.01 \%$ \\
\hline \hline
\end{tabular}

\section{Mode II Flat-Topped Modulation}

As depicted by (3) and (4), the voltage limit is actively set at $\sqrt{3} / 2 V_{m}$ according to the command voltages $v_{\text {dref }}$ and $v_{\text {qref }}$. This control scheme (noted as Mode I) injects triplen harmonics over the entire modulation index range of $(0 \sim 2 / \sqrt{3})$. Alternatively, by setting the voltage limit $V_{t h}$ at $1 / 2 V_{D C}$ rather than $\sqrt{3} / 2 V_{m}$, Fig. 3, the triplen harmonic injection is only used when the modulation index $m_{F}$ is greater than one $\left(1<m_{F} \leqslant\right.$ $2 / \sqrt{3})$. With $m_{F}$ in the range of $(0 \sim 1)$, no triplen harmonics are injected in this control scheme (noted as Mode II), which further enhances the harmonic characteristics of the flat-topped modulation.

In normal operation, the modulation index $m_{F}$ does not exceed unity and the original three-phase reference voltages $v_{a b c 0}$ are not greater than $1 / 2 V_{D C}$. With the voltage limit $V_{t h}$ set at $1 / 2 V_{D C}$, Fig. 3 , the harmonic voltage $v_{h}$ is zero and the threephase reference voltages of the flat-topped modulation $v_{a b c F}$ equal the original three-phase voltages $v_{a b c 0}$ :

$$
v_{a b c F}=v_{a b c 0}-v_{h}=v_{a b c 0}-0=v_{a b c 0} \text {. }
$$

There is no injected triplen harmonics and MMCs are operated with sinusoidal modulation in Mode II scheme during normal operation. Thus, the zero-sequence current flowing to the earth point is further reduced, compared to Mode I, and is around zero, as sinusoidal modulation will not produce zerosequence voltage. When Mode II injects triplen harmonics, it only injects those necessary to maintain the reference voltage peak of individual phase legs at $1 / 2 V_{D C}$. So the injected triplen harmonics are chosen with the objective function to limit the reference voltage in the range of $\pm 1 / 2 V_{D C}$.

Fig. 5 shows the command voltages $v_{\text {phase }- \text { I }}$ and $v_{\text {phase_II }}$ of Mode I and II control scheme with flat-topped modulation, where the modulation index $m_{F}$ increases from 0 to $2 / \sqrt{3}$. When $m_{F}$ is less than unity, triplen harmonics are only injected in Mode I scheme ( $v_{\text {phase } \_ \text {I }}$ ) while an MMC is operated with sinusoidal reference waveforms in Mode II ( $v_{\text {phase_II }}$ ). After $m_{F}$ exceeds unity, triplen harmonics are gradually injected in Mode II. With the maximum modulation index $2 / \sqrt{3}$, the two operating modes have the same reference waveforms. With $m_{F}$ in the range of $(1 \sim 2 / \sqrt{3})$, the injected triplen-series of the proposed Mode II modulation scheme changes dynamically and the THD of phase voltage is always lower than that of Mode I. This further reduces the voltage variation of transformer terminals, neutral point (where relevant) and the potential zero-sequence current.

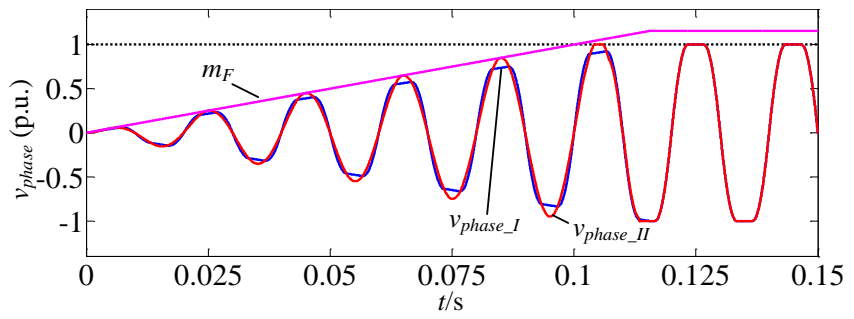

Fig. 5. Reference phase voltages $v_{\text {phase_I }}$ and $v_{\text {phase }}$ II (relative to the midpoint of the DC-link) of the proposed Mode I and II control scheme with the variation of $m_{F}$ from 0 to $2 / \sqrt{3}$, which is normalized to $1 / 2 V_{D C}$.

\section{INFLUENCE OF FLAT-TOPPED MODULATION ON MMCS}

In this section, the influence of the proposed flat-topped modulation scheme on MMC performance is discussed in normal operation and during a pole-to-pole DC fault.

\section{A. Power Losses}

The conduction losses are higher than the switching losses in MMCs for HVDC application and are the dominant part of station converter losses. Thus, only the conduction losses are discussed.

By using the enhanced flat-topped modulation scheme, the DC voltage utilization ratio is increased from $1 / 2$ to $1 / \sqrt{3}$, and thus higher converter-side AC voltage can be used. As the transferred power is fixed, the $\mathrm{AC}$ current $i_{A C F}$ is correspondingly reduced by $13.4 \%$, compared to sinusoidal modulation: 
This paper is a post-print of a paper submitted to and accepted for publication in IEEE Transaction on Power Delivery and is subject to Institution of Electrical and Electronic Engineering Copyright. The copy of record is available at IEEE Xplore Digital Library.

$$
i_{A C F}=1 / 2 \sqrt{3} I_{m 0} \sin (\omega t-\varphi)
$$

where $I_{m 0}$ is the AC current amplitude in sinusoidal modulation control; and $\varphi$ is the phase angle between the phase voltage and current. There is no zero-sequence current path for the MMC station with converter-side of the transformer unearthed. Additionally, the Mode II flat-topped modulation does not inject triplen harmonics under normal operation and thus the zero-sequence current $i_{z}$, flowing to the earth point on the converter-side, can be suppressed to around zero. As a result, the zero-sequence current is not considered in (13).

As depicted in [32], the AC current amplitude $I_{m 0}$ can be expressed in terms of the DC current $I_{D C},(13)$ is then rewritten as:

$$
i_{A C F}=\frac{\sqrt{3}}{2} \frac{4 I_{D C}}{3 m_{0} \cos \varphi} \sin (\omega t-\varphi)=\frac{4 I_{D C}}{3 m_{F} \cos \varphi} \sin (\omega t-\varphi) .
$$

Considering the DC and fundamental frequency components, the arm current is described as:

$$
i_{\text {armF }}=1 / 3 I_{D C}+1 / 2 i_{A C F}=1 / 3 I_{D C}\left[1+\frac{2 \sin (\omega t-\varphi)}{m_{F} \cos \varphi}\right] .
$$

For simplicity, the forward voltages of the IGBT and freewheel diode are assumed to be identical and denoted as $V_{f d}$. As the number of semiconductors in the current path per arm equals $N$ (the SM number per arm), according to (15), the conduction loss of the station converter can be calculated as:

$$
\begin{aligned}
P_{\text {loss } F} & =\frac{6}{2 \pi} \int_{0}^{2 \pi} N V_{f d}\left|i_{\text {armF }}\right| d(\omega t) \\
& =\frac{4 N V_{f d} I_{D C}}{\pi}\left(\frac{\sqrt{4-m_{F}^{2} \cos ^{2} \varphi}}{m_{F} \cos \varphi}+\arccos \sqrt{1-1 / 4 m_{F}^{2} \cos ^{2} \varphi}\right) .
\end{aligned}
$$

As Mode I and II have the same arm currents during normal operation, (15), the conduction losses of Mode I and II are identical and can both expressed by (16). The circulating current among the three-phase legs can be controlled around zero by proportional-resonant (PR) control, thus its influence on conduction losses is slight and not accounted for in (16).

Similarly, the conduction loss of the station converter with the sinusoidal modulation is:

$$
P_{l o s s 0}=\frac{4 N V_{f d} I_{D C}}{\pi}\left(\frac{\sqrt{4-m_{0}{ }^{2} \cos ^{2} \varphi}}{m_{0} \cos \varphi}+\arccos \sqrt{1-1 / 4 m_{0}^{2} \cos ^{2} \varphi}\right) .
$$

TABLE II

Nominal Parameters of the Test System.

\begin{tabular}{l|l}
\hline \hline \multicolumn{1}{c|}{ PARAMETER } & \multicolumn{1}{c}{ Nominal Value } \\
\hline DC-link voltage & $\pm 320 \mathrm{kV}$ \\
\hline Power rating & $1200 \mathrm{MW}$ \\
\hline AC grid voltage & $400 \mathrm{kV}$ \\
\hline SM number per arm & 256 \\
\hline SM capacitor voltage & $2.5 \mathrm{kV}$ \\
\hline SM capacitance & $7.7 \mathrm{mF}$ \\
\hline Arm inductance & $0.05 \mathrm{p} . \mathrm{u}$. \\
\hline Number of pi sections for DC cable & 10 \\
\hline$R, L$ and $C$ of DC cable & $10 \mathrm{~m} \Omega / \mathrm{km}, 0.5 \mathrm{mH} / \mathrm{km}, 0.23 \mu \mathrm{F} / \mathrm{km}$ \\
\hline DC cable length & $100 \mathrm{~km}$ \\
\hline \hline
\end{tabular}

A station converter with parameters listed in Table II is tested, where the modulation indexes are $m_{0}=\sqrt{3} / 2$ and $m_{F}=2 / \sqrt{3} m_{0}=1$. The conduction power losses of the test station with sinusoidal modulation and the enhanced flat-topped modulation are $6.2 \mathrm{MW}$ and $5.5 \mathrm{MW}$ respectively, from (17) and (16). Both Mode I and II control schemes with flat-topped modulation reduce the station conduction losses by $11 \%$, compared to sinusoidal modulation. This significantly reduces station conduction losses, yielding higher efficiency and a reduced capacity cooling system.

\section{B. SM Capacitance Requirements}

The specified maximum capacitor voltage ripple typically determines the SM capacitance requirement [21]. This section presents the process of sizing the capacitances for the MMC with the proposed flat-topped scheme.

Besides the third harmonic, the voltage $v_{h}$ contains other triplen harmonics. However, as listed in Table I, the third harmonic is the dominant frequency in the triplen harmonics and the influence of other triplen harmonics is ignored (purely third harmonic injection is a valid concept for increasing the DC voltage utilization ratio by $15.5 \%)$. Higher converter-side AC voltage is used for the flat-topped scheme due to the higher voltage generating capability:

$$
v_{A C F}=\frac{V_{D C}}{2}\left[m_{F} \sin \omega t+m_{h} \sin 3 \omega t\right]
$$

where $m_{h}$ is the modulation index of third harmonic voltage. The modulation index $m_{h}$ in Mode I control scheme with flattopped modulation is fixed at $m_{h}=0.138 m_{F}$, as listed in Table I. For the Mode II flat-topped modulation, $m_{h}$ is zero during normal operation and increases to $m_{h}=0.138 m_{F}$, in order to generate the maximum $\mathrm{AC}$ voltages.

From (18), the arm voltage is expressed as:

$$
v_{\text {arm }}=1 / 2 V_{D C}\left[1-m_{F} \sin \omega t-m_{h} \sin 3 \omega t\right] .
$$

According to (15) and (19), integrating the arm voltage multiplied by the arm current, the arm energy variation of the flat-topped modulation is

$$
\begin{aligned}
& \Delta E_{a m F}(\omega t)=\frac{1}{\omega} \int_{0}^{\omega t} V_{a m F} i_{a m F} d(\omega t)= \\
& \frac{V_{D C} I_{D C}}{6 \omega}\left\{-\frac{2}{m_{F} \cos \varphi}[\cos (\omega t-\varphi)-\cos \varphi]+m_{F}[\cos (\omega t)-1]+\frac{1}{2 \cos \varphi}[\sin (2 \omega t-\varphi)+\sin \varphi]\right\} \\
& -\frac{m_{h} V_{D C} I_{D C}}{6 \omega}\left\{-\frac{\cos (3 \omega t)-1}{3}+\frac{1}{m_{F} \cos \varphi}[1 / 2 \sin (2 \omega t+\varphi)-1 / 4 \sin (4 \omega t-\varphi)-3 / 4 \sin \varphi]\right\} .
\end{aligned}
$$

Equation (20) is the universal expression of the arm energy variation with the flat-topped modulation and the difference of the Mode I and II is the third harmonic modulation index $m_{h}$, which is set at $m_{h}=0.138 m_{F}$ and $m_{h}=0$ for Mode I and II respectively.

Similarly, the arm energy variation with the sinusoidal modulation is:

$$
\begin{aligned}
& \Delta E_{a r m 0}(\omega t)= \\
& \frac{V_{D C} I_{D C}}{6 \omega}\left\{-\frac{2}{m_{0} \cos \varphi}[\cos (\omega t-\varphi)-\cos \varphi]+m_{0}[\cos (\omega t)-1]+\frac{1}{2 \cos \varphi}[\sin (2 \omega t-\varphi)+\sin \varphi]\right\} .
\end{aligned}
$$

For the test station with parameters listed in Table II, where the modulation indexes are $m_{0}=\sqrt{3} / 2$ and $m_{F}=2 / \sqrt{3} m_{0}=1$, the energy variations per arm are obtained from (20) and (21) and illustrated in Fig. 6. The peak-to-peak energy variations per arm with sinusoidal modulation and Mode I and II schemes with flat-topped modulation are $2.15 \mathrm{MJ}, 1.61 \mathrm{MJ}$, and $1.65 \mathrm{MJ}$, 
This paper is a post-print of a paper submitted to and accepted for publication in IEEE Transaction on Power Delivery and is subject to Institution of Electrical and Electronic Engineering Copyright. The copy of record is available at IEEE Xplore Digital Library.

respectively. Thus, with $\pm 10 \%$ voltage ripple [21], their SM capacitances are $C_{S M 0}, 0.75 C_{S M 0}$, and $0.768 C_{S M 0}$, respectively. Compared with sinusoidal modulation, the SM capacitance with Mode I control scheme is reduced by $25 \%$, which significantly reduces the SM volume, weight, and capital cost. Although Mode I has the same AC currents and fundamental AC voltages as Mode II, the arm energy variation is further reduced by the injected third harmonic in Mode I.

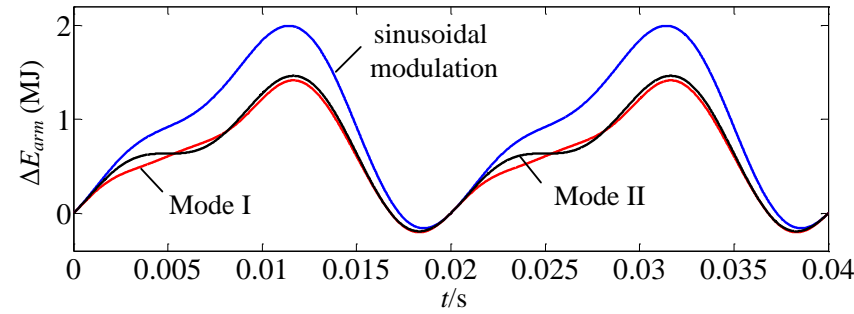

Fig. 6. Energy variations per arm with the sinusoidal modulation and flattopped scheme, for $m_{0}=\sqrt{3} / 2, m_{F}=1, V_{D C}=640 \mathrm{kV}, P=1200 \mathrm{MW}$, and $\varphi=0$.

\section{Pole-to-Pole DC Fault Currents}

As a pole-to-pole DC fault is a significant challenge for the MMC application in HVDC transmission systems, the influence of the proposed scheme on DC fault currents is discussed in this section. In the event of a DC short-circuit, high currents flow through the freewheel diodes in the halfbridge SM based MMC. The currents flow from the AC grid into the fault on the DC-side, even if the station converter is blocked immediately. The low impedance of the short-circuit path leads to a steep rise in fault current which may cause serious damage to the converters and may result in shutdown of the entire HVDC network [9, 33-35].

To limit circulating currents and DC fault currents, the arm inductance $L_{\text {arm }}$ is required and its absolute value can be calculated from the p.u. value $\alpha$ :

$$
L_{\text {arm }}=\alpha \frac{V_{L R M S}^{2}}{\omega P}=\frac{3 \alpha m^{2} V_{D C}^{2}}{8 \omega P}
$$

where $V_{L R M S}$ is the RMS line voltage and $P$ is the rated power. Equation (22) defines the relationship between the arm inductance and the modulation index and is in agreement with (9). With the same arm inductance p.u. value $\alpha$, the arm inductance is increased by a third by using the flat-topped control scheme:

$$
\frac{L_{\text {arm } F}}{L_{\text {arm } 0}}=\frac{m_{F}{ }^{2}}{m_{0}{ }^{2}}=\frac{(2 / \sqrt{3})^{2}}{1^{2}}=4 / 3 .
$$

Similarly, with the same p.u. value and the increased converter-side voltage, the converter-side transformer leakage inductance $L_{T c F}$ increases by a third:

$$
L_{T c F}=4 / 3 L_{T c 0} \text {. }
$$

On the gird-side, the grid voltage is constant and thus, with the same p.u. value, the absolute value of the grid-side leakage inductance $L_{T g F}$ remains unchanged:

$$
L_{T g F}=L_{T g 0} \text {. }
$$

Transforming the converter-side inductances to the gridside, the total AC-side inductance $L_{A C F}$ with flat-topped control scheme is the same as with sinusoidal modulation:

$$
\begin{aligned}
L_{A C F} & =\frac{L_{a r m F}+L_{T c F}}{n_{F}{ }^{2}}+L_{T_{g} F}+L_{g}=\frac{4 / 3\left(L_{a r m 0}+L_{T c 0}\right)}{\left(2 n_{0} / \sqrt{3}\right)^{2}}+L_{T g 0}+L_{g} \\
& =\frac{L_{a r m 0}+L_{T c 0}}{n_{0}{ }^{2}}+L_{T g 0}+L_{g}=L_{A C 0}
\end{aligned}
$$

where $L_{g}$ is the grid inductance; $n_{0}$ and $n_{F}$ are the ratio between the converter-side line voltage and the grid-side line voltage for sinusoidal modulation and flat-topped scheme respectively. As the grid voltage remains unchanged and the converter-side voltage is increased from 1p.u. to $2 / \sqrt{3}$ p.u. in the flat-topped scheme, as depicted by (10), the ratio $n_{F}$ is greater than $n_{0}$ :

$$
n_{F}=2 / \sqrt{3} n_{0} .
$$

For a pole-to-pole DC fault at the station terminals, which is the most serious fault case for the station, the fault current on the transformer grid-side $i_{f g}$ remains unchanged due to the constant grid voltage and the unchanged total AC-side inductance $L_{A C F}$, as shown by (26). However, due to the increased ratio $n_{F},(27)$, the fault current on the transformer converter-side $i_{f c F}$ is expected to be reduced by $13.4 \%$ by using the proposed control scheme with flat-topped modulation, which reduces the current stress on the freewheel diodes and DC circuit breakers, during a DC fault:

$$
i_{f c F}=\frac{i_{f g F}}{n_{F}}=\frac{i_{f g 0}}{2 n_{0} / \sqrt{3}}=1 / 2 \sqrt{3} i_{f c 0}=0.866 i_{f c 0} .
$$

\section{Performance Evaluation}

The MMC performance with the proposed flat-topped modulation is assessed using a point-to-point HVDC link model as shown in Fig. 7, in the MATLAB/Simulink ${ }^{\circledR}$ environment. In the test system, $\mathrm{MMC}_{1}$ imports rated active power from the AC grid $G_{1}$ to the DC-side at unity power factor while $\mathrm{MMC}_{2}$ is configured to regulate the DC-link voltage level at $\pm 320 \mathrm{kV}$, also at unity power factor. Both the stations $\left(\mathrm{MMC}_{1}\right.$ and $\left.\mathrm{MMC}_{2}\right)$ are modeled as conventional halfbridge SM based MMCs using average models and have the same parameters listed in Table II.

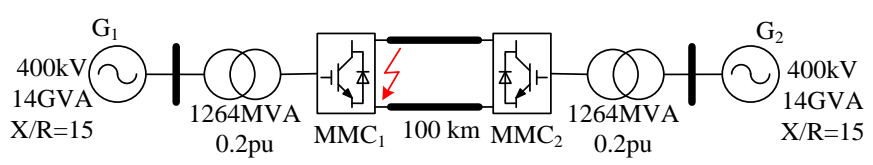

Fig. 7. Point-to-point HVDC link using average model.

Although Mode I control scheme reduces the third harmonic by $33 \%$ compared to that of SVM, the zero-sequence current still flows to the earthing point on the converter-side of the transformer. Thus, Mode I scheme is applicable for MMCHVDC system with transformer converter-side unearthed and uses conventional $\mathrm{Yn} / \mathrm{D}$ transformer with grid-side earthed in the test HVDC link. To keep accordance, the Yn/D transformer is adopted in Section IV A and C.

To demonstrate the significant advantage of the Mode II scheme over SVM, in terms of zero-sequence current reduction, the $\mathrm{Y} / \mathrm{Yn}$ configuration of the transformer earthed on converter-side is used in Section IV B. This transformer 
This paper is a post-print of a paper submitted to and accepted for publication in IEEE Transaction on Power Delivery and is subject to Institution of Electrical and Electronic Engineering Copyright. The copy of record is available at IEEE Xplore Digital Library.

arrangement is also used in Yangshan station of the Zhoushan multi-terminal HVDC project, Fig. 1 (a). The three-phase earthing reactor as shown in Fig. 2 (a) is connected between the grid and the interface transformer to properly earth the grid-side.

TABLE III

AC voltages of the Test HVDC link.

\begin{tabular}{l|l|l|l|r}
\hline \hline \multicolumn{1}{c|}{ PARAMETER } & Sinusoidal modulation & \multicolumn{1}{c|}{ SV modulation } & Mode I & Mode II \\
\hline Transformer grid-side and converter-side voltages & $400 \mathrm{kV} / 339 \mathrm{kV}$ & $400 \mathrm{kV} / 392 \mathrm{kV}$ & $400 \mathrm{kV} / 392 \mathrm{kV}$ & $400 \mathrm{kV} / 392 \mathrm{kV}$ \\
\hline Modulation index & $\sqrt{3} / 2$ & 1 & 1 & 1 \\
\hline \hline
\end{tabular}

Although the grid voltages are the same, higher converterside $\mathrm{AC}$ voltage is used for the flat-topped control scheme due to its higher voltage generating capability, as aforementioned. Thus, with the sinusoidal modulation index $m_{0}$ set at $\sqrt{3} / 2$, the converter-side RMS line voltages of sinusoidal modulation and the flat-topped scheme are obtained as $339 \mathrm{kV}$ and $392 \mathrm{kV}$ respectively, Table III, according to (9) and (10).

\section{A. Comparison between Sinusoidal Modulation and Proposed Control Scheme}

The MMC performance with the proposed control scheme under normal operation is compared to that with sinusoidal modulation, Fig. 8, where only the waveforms of $\mathrm{MMC}_{1}$ are displayed for simplicity.
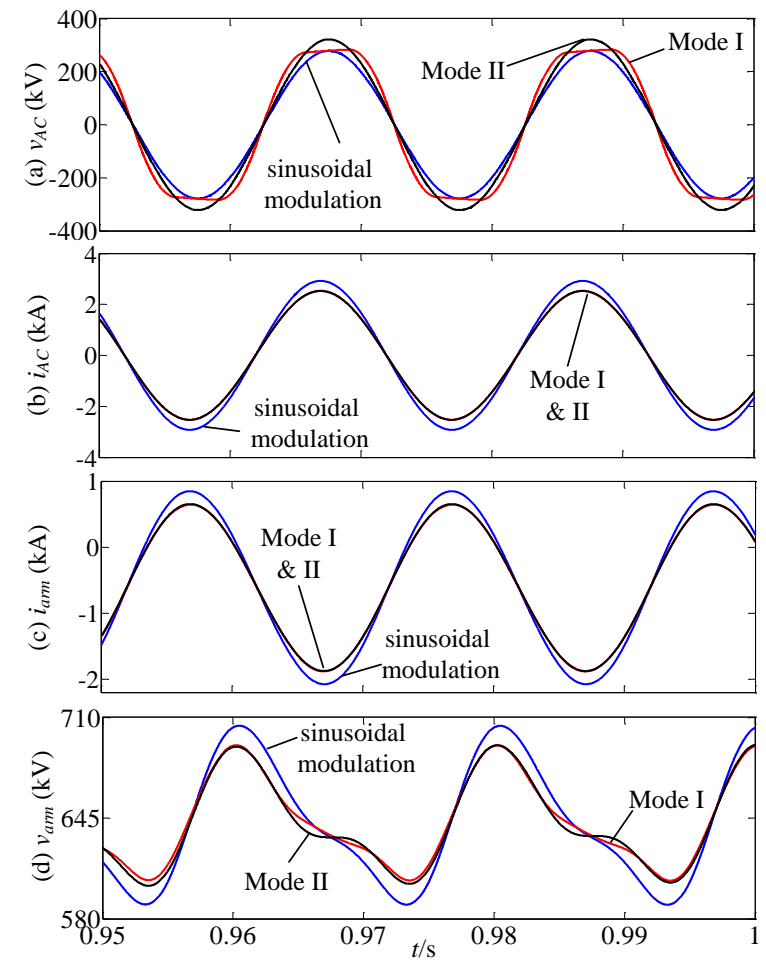

Fig. 8. Comparison between sinusoidal modulation and proposed control scheme in normal operation: (a) AC phase voltages referenced to the DC-link mid-point, (b) AC currents, (c) arm currents, and (d) arm voltages.

The output phase voltages referenced to the mid-point of the DC-link are shown in Fig. 8 (a). The voltage peaks with sinusoidal modulation and Mode I control scheme using flattopped modulation are both controlled around $277 \mathrm{kV}$. However, benefitting from the injected triplen harmonics, the fundamental voltage amplitude of the latter is around $320 \mathrm{kV}$, higher than sinusoidal modulation control $(277 \mathrm{kV})$.
When the modulation index does not exceed unity in Mode II, the reference voltage of the converter does not contain triplen harmonics and has higher amplitude $(320 \mathrm{kV})$ compared to conventional sinusoidal modulation, Fig. 8 (a). Once the amplitude of the demand voltage, $v_{a b c 0}$, exceeds the threshold $V_{t h}$ (hence sinusoidal modulation will generate distorted phase voltages), triplen harmonics are injected by the proposed Mode II flat-topped modulation scheme to generate a higher fundamental voltage.

As shown in Fig. 8 (b), the injected triplen harmonics of Mode I only exist in the converter phase voltages referenced to the mid-point of the DC-link and do not affect the quality of the line voltage and current as they are co-phasal. With the same transferred power of $1200 \mathrm{MW}$, the transformer converter-side current peak with the proposed scheme is reduced from about $2.9 \mathrm{kA}$ to $2.5 \mathrm{kA}$.

As the arm current is the sum of one third the DC current and half the AC current, from Fig. 8 (c), the arm current peaks with the enhanced flat-topped modulation scheme are reduced approximately by $10 \%$, compared with sinusoidal modulation, yielding lower semiconductor current stresses and conduction losses. Fig. 8 (d) shows the simulated arm voltages. With the same SM capacitance, the peak-to-peak ripple with sinusoidal modulation and with Mode I and II schemes are $125 \mathrm{kV}, 93 \mathrm{kV}$, and $95 \mathrm{kV}$ respectively, which are in good agreement with the calculated values from (21) and (20).

To reduce computation time and accelerate the simulation, the average model is used in this work instead of the detailed model [36-40]. As only one capacitor is used per arm in the average model, SM capacitor voltage balancing is not considered. By using a sorting algorithm [3, 41, 42], SM capacitor voltages can be balanced in a detailed model with the proposed flat-topped modulation.

\section{B. Comparison between SVM and Mode II Control Scheme}

In the Mode II control scheme, the voltage threshold $V_{t h}$ is set at $1 / 2 V_{D C}$. During normal operation, the DC voltage $V_{D C}$ is controlled at the rated value $(640 \mathrm{kV})$ and the amplitude of the command voltage $v_{a b c 0}$ is less than or equal to $1 / 2 V_{D C}$ $(1 / 2 \times 640 \mathrm{kV}=320 \mathrm{kV})$. Thus, no triplen harmonics are injected in normal operation, as shown in Fig. 8 (a). For a DC fault that causes a reduction in the DC voltage (lower than $640 \mathrm{kV}$ ), the MMCs cannot generate the required voltage with sinusoidal modulation, when the amplitude of the command voltages $v_{a b c 0}$ is greater than half the DC voltage. Triplen harmonics are then injected, as presented in Section II, to improve the voltage generating capability of the MMCs. This also applies to the 
This paper is a post-print of a paper submitted to and accepted for publication in IEEE Transaction on Power Delivery and is subject to Institution of Electrical and Electronic Engineering Copyright. The copy of record is available at IEEE Xplore Digital Library.

operating condition where the AC grid voltage increases abnormally.

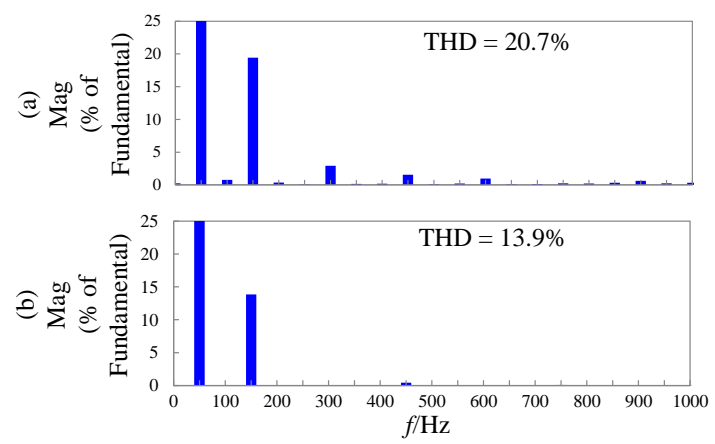

Fig. 9. FFT analysis of output phase voltages with: (a) SVM and (b) flattopped control scheme with $m_{F}=2 / \sqrt{3}$.

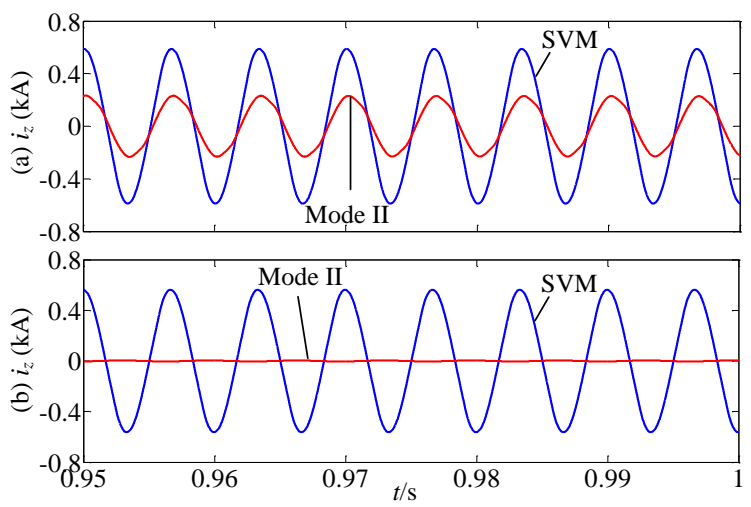

Fig. 10. Transformer converter-side zero-sequence currents with SVM and Mode II control scheme using flat-topped modulation: (a) abnormal situation and (b) normal operation.

Fig. 9 shows the FFT analysis of output phase voltage of MMC with $m_{F}=2 / \sqrt{3}$. The third harmonic dominates the triplen harmonics in the proposed flat-topped modulation and is lower than that with SVM, which is in agreement with Table I. In addition to third harmonic, all other triplen harmonics of the flat-topped modulation are lower than that with SVM. The THD of output phase voltage is therefore reduced from $20.7 \%$ to $13.9 \%$, yielding a lower zero-sequence voltage component. This significantly lowers the converter-side zero-sequence current that flows to earth through the neutral point of $\mathrm{Y} / \mathrm{Yn}$ transformer with converter-side earthed, Fig. 10 (a).

The output voltages of the MMC can be regulated well by the flat-topped scheme over the entire operating range, in addition to no-load and rated operating conditions.

The triplen harmonic content of SVM remains unchanged with the reduction of modulation index and the THD of phase voltage is always around 20\%. Differently, the triplen harmonics are reduced gradually in the proposed Mode II control scheme with flat-topped modulation, after the remote $\mathrm{DC}$ fault is eliminated or the $\mathrm{AC}$ grid voltage restores to rated value. Once the system recovers from the abnormal situation, the modulation waveforms return to sinusoidal and do not contain triplen harmonics. As a result, the zero-sequence current $i_{z}$ is close to zero in normal operation and lower than that with SVM, Fig. 10 (b).
The high triplen harmonics in SVM cause zero-sequence current flowing to earth through the neutral point of $\mathrm{Y} / \mathrm{Yn}$ transformer with the converter-side earthed, Fig. 10 (a). Due to the zero-sequence current, the three-phase currents (converterside) are not balanced, although the three-phase grid voltages are sinusoidal and balanced.

The Y/Yn transformer in the Zhoushan HVDC project, Fig. 1 (a), is taken as an example to demonstrate that the proposed flat-topped modulation can reduce the zero-sequence current flowing to earth, in the HVDC system with converter-side of the transformer earthed. In addition to the $\mathrm{Y} / \mathrm{Yn}$ arrangement, all the HVDC systems with the transformer converter-side earthed have the issue of the zero-sequence current when SVM is used, e.g. D/Yn transformer with converter-side earthed [2325], three-phase earthing reactor and the zig-zag transformer providing an earthing point [26-30], etc. Thus the flat-topped modulation scheme is an attractive proposition to reduce the zero-sequence current.

\section{Performance during a Pole-to-Pole DC Fault}

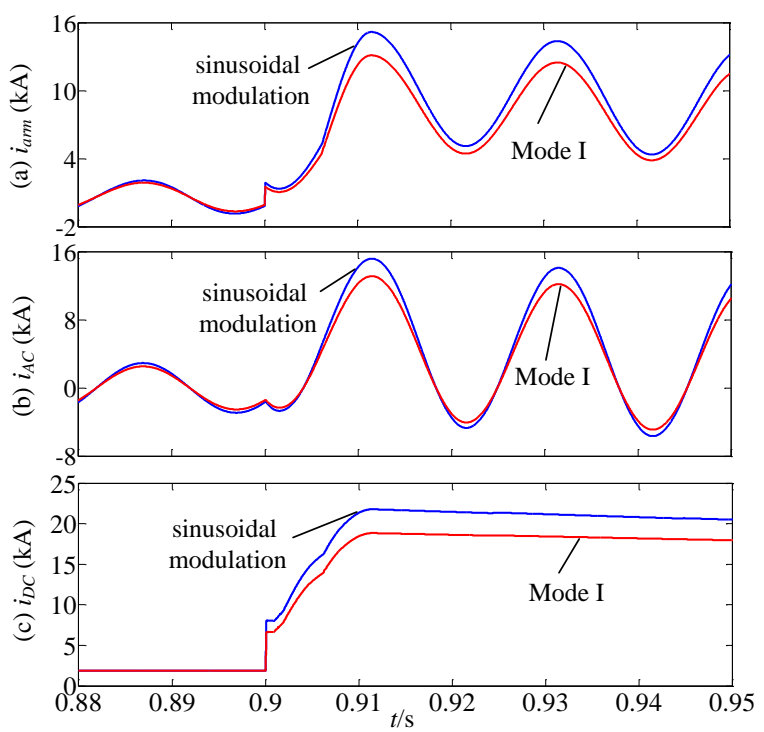

Fig. 11. Comparison between sinusoidal modulation and proposed control scheme during pole-to-pole DC fault: (a) arm currents, (b) AC currents, and (c) DC currents.

In this scenario, a permanent pole-to-pole DC fault is applied at the terminals of $\mathrm{MMC}_{1}$ at $t=0.9 \mathrm{~s}$, Fig. 7 . Both the stations are blocked after the fault and the circuit breaker action is not considered. As illustrated in Fig. 11 (a), the fault arm current peak is reduced from $15.2 \mathrm{kA}$ to $13.1 \mathrm{kA}$ by using the proposed control scheme, yielding lower fault current stresses on freewheel diodes. This is in good agreement with (28). The fault AC currents have the same peaks with arm currents and are also reduced to $86.6 \%$, Fig. 11 (b). Similarly, the fault DC current peak is reduced by $13.4 \%$ and thus the lower capacity DC circuit breakers can potentially be used to isolate the fault, which reduces the capital cost and conduction losses of circuit breakers.

Only the waveforms for Mode I are shown in Fig. 11 for simplicity as Mode II has an identical effect on the reduction of fault current with Mode I. 
This paper is a post-print of a paper submitted to and accepted for publication in IEEE Transaction on Power Delivery and is subject to Institution of Electrical and Electronic Engineering Copyright. The copy of record is available at IEEE Xplore Digital Library.

\section{CONCLUSION}

The enhanced flat-topped modulation of MMC is proposed in this paper and the harmonic characteristics are presented by Fourier analysis. Compared to SVM, the dominant third harmonic is reduced by $33 \%$ and thus the voltage variation of the transformer terminals, neutral point and the potential zerosequence current are correspondingly lowered. The Mode I control scheme with flat-topped modulation is a preferred option for the HVDC station without the transformer converter-side earthed, as its SM capacitance is slightly lower than that of Mode II. However, considering the zero triplen harmonics in Mode II during normal operation, Mode II control scheme provides a preferable option for the HVDC station with converter-side earthed.

Due to the injected triplen harmonics and higher voltage generating capability compared to sinusoidal modulation, SM capacitance with flat-topped scheme is reduced by $25 \%$, which significantly reduces both the volume and capital cost of SMs. Additionally, station converter conduction losses are reduced by $11 \%$ and the capacity of cooling system is thus reduced. Although the converter-side voltage is increased, the DC fault currents are expected to be reduced by $13.4 \%$, yielding lower fault current stresses on semiconductors and DC circuit breakers. Simulation results are in good agreement with the analysis, which demonstrates the effectiveness of the presented modulation scheme.

\section{REFERENCES}

[1] G. Minyuan and X. Zheng, "Modeling and Control of a Modular Multilevel Converter-Based HVDC System Under Unbalanced Grid Conditions," Power Electronics, IEEE Transactions on, vol. 27, pp. 4858-4867, 2012.

[2] D. Montesinos-Miracle, M. Massot-Campos, J. Bergas-Jane, S. GalceranArellano, and A. Rufer, "Design and Control of a Modular Multilevel DC/DC Converter for Regenerative Applications," Power Electronics, IEEE Transactions on, vol. 28, pp. 3970-3979, 2013.

[3] D. Fujin and C. Zhe, "A Control Method for Voltage Balancing in Modular Multilevel Converters," IEEE Trans. Power Electron., vol. 29, pp. 66-76, 2014.

[4] S. Qiang, L. Wenhua, L. Xiaoqian, R. Hong, X. Shukai, and L. Licheng, "A Steady-State Analysis Method for a Modular Multilevel Converter," Power Electronics, IEEE Transactions on, vol. 28, pp. 3702-3713, 2013.

[5] Z. Ming, H. Long, Y. Wenxi, and L. Zhengyu, "Circulating Harmonic Current Elimination of a CPS-PWM-Based Modular Multilevel Converter With a Plug-In Repetitive Controller," IEEE Trans. Power Electron., vol. 29, pp. 2083-2097, 2014.

[6] U. N. Gnanarathna, A. M. Gole, and R. P. Jayasinghe, "Efficient Modeling of Modular Multilevel HVDC Converters (MMC) on Electromagnetic Transient Simulation Programs," IEEE Trans. Power Del., vol. 26, pp. 316-324, 2011.

[7] G. P. Adam, O. Anaya-Lara, G. M. Burt, D. Telford, B. W. Williams, and J. R. McDonald, "Modular multilevel inverter: Pulse width modulation and capacitor balancing technique," IET. Power Electron., vol. 3, pp. 702-715, 2010.

[8] M. A. Perez, S. Bernet, J. Rodriguez, S. Kouro, and R. Lizana, "Circuit Topologies, Modeling, Control Schemes, and Applications of Modular Multilevel Converters," IEEE Trans. Power Electron., vol. 30, pp. 4-17, 2015.

[9] G. P. Adam, K. H. Ahmed, S. J. Finney, K. Bell, and B. W. Williams, "New Breed of Network Fault-Tolerant Voltage-Source-Converter HVDC Transmission System," IEEE Trans. Power Sys., vol. 28, pp. 335-346, 2013.

[10]I. A. Gowaid, G. P. Adam, A. M. Massoud, S. Ahmed, D. Holliday, and B. W. Williams, "Quasi Two-Level Operation of Modular Multilevel
Converter for Use in a High-Power DC Transformer With DC Fault Isolation Capability," IEEE Trans. Power Electron., vol. 30, pp. 108-123, 2015.

[11]R. Li, G. Adam, D. Holliday, J. Fletcher, and B. Williams, "Hybrid Cascaded Modular Multilevel Converter with DC Fault Ride-Through Capability for HVDC Transmission System," IEEE Trans. Power Del., vol. PP, pp. 1-1, 2015.

[12]R. Picas, S. Ceballos, J. Pou, J. Zaragoza, G. Konstantinou, and V. G. Agelidis, "Improving capacitor voltage ripples and power losses of modular multilevel converters through discontinuous modulation," in Industrial Electronics Society, IECON 2013 - 39th Annual Conference of the IEEE, 2013, pp. 6233-6238.

[13]R. Picas, S. Ceballos, J. Pou, J. Zaragoza, G. Konstantinou, and V. G. Agelidis, "Closed-Loop Discontinuous Modulation Technique for Capacitor Voltage Ripples and Switching Losses Reduction in Modular Multilevel Converters," IEEE Trans. Power Electron., vol. 30, pp. 47144725, 2015

[14]A. Rasic, U. Krebs, H. Leu, and G. Herold, "Optimization of the modular multilevel converters performance using the second harmonic of the module current," in Power Electronics and Applications, 2009. EPE '09. 13th European Conference on, 2009, pp. 1-10.

[15]F. Blaabjerg, A. Isidori, and F. M. Rossi, "Impact of modulation strategies on power devices loading for $10 \mathrm{MW}$ multilevel wind power converter," in Power Electronics for Distributed Generation Systems (PEDG), 2012 3rd IEEE International Symposium on, 2012, pp. 751-758.

[16]R. Li and D. G. Xu, "Parallel Operation of Full Power Converters in Permanent-Magnet Direct-Drive Wind Power Generation System," IEEE Trans. Ind. Electron., vol. 60, pp. 1619-1629, 2013.

[17]M. Saeedifard and R. Iravani, "Dynamic Performance of a Modular Multilevel Back-to-Back HVDC System," IEEE Trans. Power Del., vol. 25, pp. 2903-2912, 2010.

[18]A. Lesnicar and R. Marquardt, "An innovative modular multilevel converter topology suitable for a wide power range," in Power Tech Conference Proceedings, 2003 IEEE Bologna, 2003, p. 6 pp. Vol.3.

[19]G. Adam, R. Li, D. Holliday, S. Finney, L. Xu, B. Williams, et al., "Continued Operation of Multi-Terminal HVDC Networks Based on Modular Multilevel Converters," CIGRE, pp. 1-8, 2015.

[20]K. H. Ahmed and G. P. Adam, "New modified staircase modulation and capacitor balancing strategy of 21-level modular multilevel converter for HVDC transmission systems," in Power Electronics, Machines and Drives (PEMD 2014), 7th IET International Conference on, 2014, pp. 16.

[21]J. Peralta, H. Saad, S. Dennetiere, J. Mahseredjian, and S. Nguefeu, "Detailed and Averaged Models for a 401-Level MMC-HVDC System," IEEE Trans. Power Del., vol. 27, pp. 1501-1508, 2012.

[22]Q. Tu, Z. Xu, and L. Xu, "Reduced Switching-Frequency Modulation and Circulating Current Suppression for Modular Multilevel Converters," IEEE Transactions on Power Delivery, vol. 26, pp. 2009-2017, 2011.

[23]J. Rafferty, X. Lie, and J. Morrow, "Analysis of voltage source converterbased high-voltage direct current under DC line-to-earth fault," IET. Power Electron., vol. 8, pp. 428-438, 2015.

[24]T. Lianxiang and O. Boon-Teck, "Managing zero sequence in voltage source converter," in Industry Applications Conference, 2002. 37th IAS Annual Meeting. Conference Record of the, 2002, pp. 795-802 vol.2.

[25]Y. Jin, J. E. Fletcher, and J. O'Reilly, "Short-Circuit and Ground Fault Analyses and Location in VSC-Based DC Network Cables," IEEE Trans. Ind. Electron., vol. 59, pp. 3827-3837, 2012.

[26]X. Li, Y. Ma, B. Yue, W. Ma, and D. Chen, "Study on Discharge Characteristics of DC System in Zhoushan Multi-Terminal VSC-HVDC Transmission Project," CIGRE, pp. 1-13, 2015.

[27]H. Zhou, Y. Shen, M. Li, J. TIAN, X. DENG, X. CHEN, et al., "Research on insulation coordination for converter stations of Zhoushan multiterminal VSC-HVDC transmission project," Power System Technology, vol. 37, pp. 879-890, 2013.

[28]D. Xu, W. Dongju, and S. Yang, "Research on transient overvoltage for converter station of Zhoushan multi-terminal VSC-HVDC project," Power System Protection and Control, vol. 41, pp. 111-119, 2013.

[29]W. Haitian, T. Guangfu, H. Zhiyuan, and Y. Jie, "Efficient Grounding for Modular Multilevel HVDC Converters (MMC) on the AC Side," IEEE Trans. Power Del., vol. 29, pp. 1262-1272, 2014.

[30]J. Jae-Jung, C. Shenghui, L. Younggi, and S. Seung-Ki, "A cell capacitor energy balancing control of MMC-HVDC under the AC grid faults," in 
This paper is a post-print of a paper submitted to and accepted for publication in IEEE Transaction on Power Delivery and is subject to Institution of Electrical and Electronic Engineering Copyright. The copy of record is available at IEEE Xplore Digital Library.

Power Electronics and ECCE Asia (ICPE-ECCE Asia), 2015 9th International Conference on, 2015, pp. 1-8.

[31]J. E. Fletcher, "Design, Analysis and Control of a Synchronous Reluctance Machine," Ph.D Thesis, Department of Computing and Electrical Engineering, Heriot-Watt University, 1995.

[32]R. Li, J. E. Fletcher, L. Xu, D. Holliday, and B. W. Williams, "A Hybrid Modular Multilevel Converter with Novel Three-level Cells for DC Fault Blocking Capability," IEEE Trans. Power Del., vol. PP, pp. 1-1, 2015.

[33]P. Samuel, R. Gupta, and D. Chandra, "Grid interface of wind power with large split-winding alternator using cascaded multilevel inverter," in IEEE Trans. Energy Convers vol. 26, ed, 2011, pp. 299-309.

[34]M. Hamzeh, A. Ghazanfari, H. Mokhtari, and H. Karimi, "Integrating Hybrid Power Source Into an Islanded MV Microgrid Using CHB Multilevel Inverter Under Unbalanced and Nonlinear Load Conditions," IEEE Trans. Energy Convers, vol. 28, pp. 643-651, 2013.

[35]S. Debnath, Q. Jiangchao, B. Bahrani, M. Saeedifard, and P. Barbosa, "Operation, Control, and Applications of the Modular Multilevel Converter: A Review," IEEE Trans. Power Electron., vol. 30, pp. 37-53, 2015.

[36]J. Peralta, H. Saad, S. Dennetiere, J. Mahseredjian, and S. Nguefeu, "Detailed and Averaged Models for a 401-Level MMC\&\#x2013;HVDC System," IEEE Trans. Power Del., vol. 27, pp. 1501-1508, 2012.

[37]X. Jianzhong, A. M. Gole, and Z. Chengyong, "The Use of AveragedValue Model of Modular Multilevel Converter in DC Grid," IEEE Trans. Power Del., vol. 30, pp. 519-528, 2015.

[38]F. B. Ajaei and R. Iravani, "Enhanced Equivalent Model of the Modular Multilevel Converter," IEEE Trans. Power Del., vol. 30, pp. 666-673, 2015.

[39]H. Saad, J. Peralta, S. Dennetiere, J. Mahseredjian, J. Jatskevich, J. A. Martinez, et al., "Dynamic Averaged and Simplified Models for MMCBased HVDC Transmission Systems," IEEE Trans. Power Del., vol. 28, pp. 1723-1730, 2013.

[40]R. Li, L. Xu, D. Holliday, F. Page, S. J. Finney, and B. W. Williams, "Continuous Operation of Radial Multiterminal HVDC Systems Under DC Fault," IEEE Trans. Power Del., vol. 31, pp. 351-361, 2016.

[41]Q. Jiangchao and M. Saeedifard, "Reduced Switching-Frequency Voltage-Balancing Strategies for Modular Multilevel HVDC Converters," IEEE Trans. Power Del., vol. 28, pp. 2403-2410, 2013.

[42]S. Gum Tae, L. Hee-Jin, N. Tae Sik, C. Yong-Ho, L. Uk-Hwa, B. SeungTaek, et al., "Design and Control of a Modular Multilevel HVDC Converter With Redundant Power Modules for Noninterruptible Energy Transfer," IEEE Trans. Power Del., vol. 27, pp. 1611-1619, 2012.

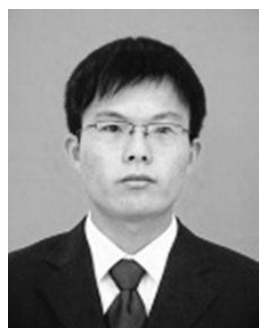

Rui Li received the M.S. and Ph.D degrees in electrical engineering from Harbin Institute of Technology, Harbin, China, in 2008 and 2013, respectively. Since 2013 , he has been working as a research associate with University of Strathclyde in Glasgow, UK.

His research interests include HVDC transmiision system, grid integration of renewable power, power electronic converters, and energy conversion.

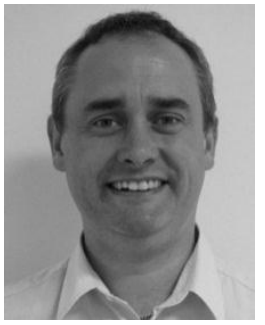

John E. Fletcher (M'12-SM'14) received the B.Eng. (with first class honors) and Ph.D. degrees in electrical and electronic engineering from HeriotWatt University, Edinburgh, U.K., in 1991 and 1995, respectively. Until 2007, he was a Lecturer at HeriotWatt University. From 2007 to 2010, he was a Senior Lecturer with the University of Strathclyde, Glasgow, U.K. He is currently a Professor with the University of New South Wales, Sydney, Australia.

His research interests include distributed and renewable integration, silicon carbide electronics, pulsed-power applications of power electronics, and the design and control of electrical machines. Prof. Fletcher is a Charted Engineer in the U.K. and a Fellow of the Institution of Engineering and Technology.

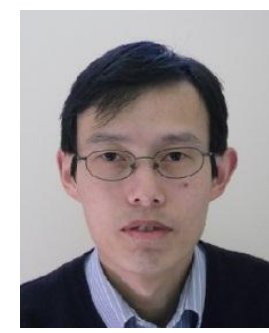

Lie Xu (M'03-SM'06) received the B.Sc. degree in Mechatronics from Zhejiang University, Hangzhou, China, in 1993, and the Ph.D. degree in Electrical Engineering from the University of Sheffield, Sheffield, UK, in 1999.

He is currently with the Department of Electronic \& Electrical Engineering, University of Strathclyde, Glasgow, UK. He previously worked in Queen's University of Belfast and ALSTOM T\&D, Stafford, UK. His research interests include power electronics, wind energy generation and grid integration, and application of power electronics to power systems.

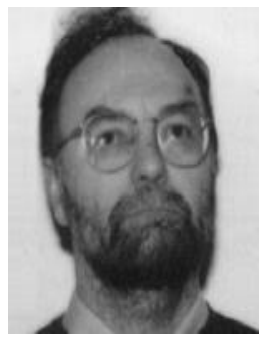

B. W. Williams received the M.Eng.Sc. degree in electrical and electronic engineering from the University of Adelaide, Australia, in 1978, and the $\mathrm{Ph} . \mathrm{D}$. degree in electrical and electronic engineering from Cambridge University, Cambridge, U.K., in 1980.

After seven years as a Lecturer at Imperial College, University of London, U.K., he was appointed to a Chair of Electrical Engineering at Heriot-Watt University, Edinburgh, U.K, in 1986. He is currently a Professor at Strathclyde University, UK. His teaching covers power electronics (in which he has a free internet text) and drive systems.

His research activities include power semiconductor modelling and protection, converter topologies, soft switching techniques, and application of ASICs and microprocessors to industrial electronics. 